\title{
Field Assessment of Agronomic Performance, Resistance to Aflatoxin, and Fumonisin Accumulation in Selected Maize Inbred Lines in Kenya
}

\author{
Ouko Abigael ${ }^{1}{ }^{\text {* }}$, Okoth Sheila ${ }^{1}$, Amugune Nelson ${ }^{1}$, Vesa Joutsjoki ${ }^{2}$ \\ ${ }^{1}$ School of Biological Sciences, University of Nairobi, Nairobi, Kenya \\ ${ }^{2}$ Natural Resources Institute Finland, Jokioinen, Finland
}

Email address:

abbykongete@gmail.com (O. Abigael)

${ }^{*}$ Corresponding author

To cite this article:

Ouko Abigael, Okoth Sheila, Amugune Nelson, Vesa Joutsjoki. Field Assessment of Agronomic Performance, Resistance to Aflatoxin, and Fumonisin Accumulation in Selected Maize Inbred Lines in Kenya. Agriculture, Forestry and Fisheries. Vol. 7, No. 4, 2018 , pp. 94-100. doi: 10.11648/j.aff.20180704.11

Received: November 6, 2018; Accepted: November 29, 2018; Published: December 20, 2018

\begin{abstract}
Aspergillus flavus and Fusarium verticilloides cause contamination of maize (Zea mays) and concern to maize farmers because they reduce maize quantity and quality. These fungi produce mycotoxins, some of which are poisonous to both humans and animals. Over 300 mycotoxins are known but in this study aflatoxins and fumonisins produced by A. flavus and $F$. verticilloides, respectively, are reported due to their health concerns in Africa. Contamination of maize grain by these fungi occurs before harvest and selection of maize parental lines resistant to accumulation of aflatoxin, and fumonisin for breeding purposes is the easiest strategy to reduce consumption of maize grains contaminated by these toxins. In addition to selecting for resistant lines, breeders would prefer inbred lines with top performing agronomic traits. This study aimed at identifying possible source of resistance together with good agronomic traits among 23 maize inbred lines (13 sourced from the MAIZE Competitive Grants Initiative, International Maize and Wheat Improvement Centre and 10 from Agricultural Research Council, South Africa). The lines were planted in two blocks; Aspergillus, and Fusarium, in a randomized complete-block design for two seasons in one location in Kenya. Germination rate, days to silking, and days to anthesis were determined in each line. Inoculation of the maize ears was done at silking with three toxigenic strains of A. flavus for Aspergillus block, and $F$. verticilloides for Fusarium block. Aflatoxins and fumonisins concentration in the kernels was determined using Enzyme-linked immunosorbent assay (ELISA). A positive significant correlation ( $\mathrm{r}=0.9458846, \mathrm{P}=<9.845 \mathrm{e}-12)$ occurred between days to anthesis and days to silking, aflatoxins and fumonisins $(r=0.43149988, P \leq 0.05)$ accumulated in the inbred lines. A negative correlation between germination and accumulated fumonisin levels $(r=-0.5156961, \mathrm{P}=0.01178)$, days to pollen shed and aflatoxin $(r=-0.4617732, P=0.02654)$ was revealed. Apart from being good germinating lines and drought tolerant, CML 390 and CML 247 accumulated least fumonisin, and aflatoxin levels compared to the other germplasms. These two lines with consistent low aflatoxin, and fumonisin levels may, therefore be useful sources of resistance for maize breeding programs to reduce both aflatoxin and fumonisn contamination in maize. Four aflatoxin resistant lines (CB 222, CML 495 and CML 444) and one (CKL05003) fumonisin resistant line showed good agronomic traits. The lines may be suitable for breeding for resistance to aflatoxins, and fumonisins respectively in maize.
\end{abstract}

Keywords: Maize Inbred Lines, Germination, Silking, Pollen Shed, Aflatoxin and Fumonisin

\section{Introduction}

Maize (Zea mays L.) is a staple food in most African countries majorly in the eastern and southern regions. In Kenya, $96 \%$ of the population depends on the crop and it accounts for about $40 \%$ of the daily calorie intake consumed at a rate of 258/person /day [1,2]. The food security considerations in Kenya are dominated by maize crop with a per capita consumption of $98 \mathrm{~kg}$ per annum. In children, maize forms a major portion of the gruel used for weaning, 
and in animal feed, maize grain is a crucial component hence the increase in its demand [2, 3]. Maize farming in Kenya is dominated by small scale farmers who contribute $75 \%$ of the total produce on 2 million hectares with average yield of 1.21.6 tons per hectare [2]. However, its production is lowered by various diseases including fungi (ear rots, foliar diseases, smuts, stalk rots among others), bacteria (Stewart's wilt, stalk rot, bacterial leaf stripe among others), viruses (maize lethal necrosis, maize stripe virus, maize steak virus, maize chlorotic dwarf virus among others) and mollicutes (maize bushy stunt phytoplasma, corn stunt spiroplasma among others) [4].

Among fungi, Aspergillus and Fusarium are known to constrain maize production by reducing its quality and quantity [2, 5, 6]. These fungi produce aflatoxins and fumonisins, respectively, as secondary matabolites, some of which are poisonous to both humans and animals. Aflatoxins production starts in the fields soon after maize kernels are colonized by $A$. flavus and accumulates during maturation of the kernels [2] whereas fumonisin contamination of the maize grains due to infection by $F$. verticillioides can occur at all developmental stages, and intensifies in the field since most Kenyan farmers leave maize in the field to dry beyond physiological maturity. This often coincides with the rains resulting in increased fumonisin accumulation. The Kenyan human and animal populations are directly exposed to regular doses of aflatoxins and fumonisins through maize ingestion $[2,8]$. Contaminated cereal grains, commercially processed maize products, dairy concentrates made from moulddamaged grains and crop residues for homemade dairy concentrates are primary routes of aflatoxins and fumonisins consumption in man and animals $[2,8]$.

Aflatoxin is classified as class 1 carcinogen by Internationaion Centre for Cancer Research [2, 7]. Chronic exposure to aflatoxins is known to cause cancer while consumption at high levels result to death in both humans and other animals. Outbreaks of aflatoxicosis, resulting into deaths, have been reported in Kenya yearly since 1981, in eastern Kenya, following consumption of aflatoxin contaminated maize. The 2004 aflatoxicosis was one of the most episodes of human aflatoxin poisoning with 317 cases and 125 deaths reported. Aspergillus flavus has been the cause of contamination [9]. Aflatoxicoses in humans have been reported in other countries in Africa. Tanzania is a major maize producer in the Sub-Saharan Africa and is among top 25 maize producers in the world. However, aflatoxin contamination is commonly reported in the eastern (Morogoro) and Western (Shinyanga) zones of Tanzania. In Nigeria, aflatoxin levels are as high as $1000-5000 \mu \mathrm{g} / \mathrm{kg}$ in maize, groundnuts, rice and millet. Increased liver cancer cases in Uganda are attributed to consumption of aflatoxin contaminated maize and peanuts $[10,2]$.

Though fumonisin research is less documented compared to aflatoxin, fumonisin research has been extensively done in South Africa where $F$. verticilloides is the most prevalent ear rot causing fungi [6]. In the Transkei region of South Africa, and China, consumption of maize contaminated with fumonisin has been associated with increased cases of oesophageal cancer. A study conducted to assess levels of fumonisin contamination of maize stored and consumed in rural households in Malawi recorded fumonisin levels ranging between $1-7 \mathrm{mg} / \mathrm{kg}$. Extremely high fumonisin contamination in maize ranging from $8,240-16,690 \mathrm{mg} / \mathrm{kg}$ due to $F$. verticilloides infection has also been reported in Benin while in Kenya, fumonisin contamination has been reported in the eastern part in areas where aflatoxin outbreaks have been frequently reported $[8,11]$.

A concentration of $10 \mu \mathrm{g} / \mathrm{kg}$ is the acceptable limit of total aflatoxins in maize for both human and animal consumption as set by the Kenya Bureau of Standards (KBS). This limit is lower than $20 \mu \mathrm{g} / \mathrm{kg}$ limit set by the United States Food and Drug Administration [12]. A concentaration limit of $2 \mathrm{mg} / \mathrm{kg}$ in maize is the recommended limit for fumonisin consumption in Kenya both for human and animal as recommended by the World Health Organization (WHO) (1969) [2, 13-15]. The challenge is that testing of food and feed quality in Kenya has not been effective because most maize produce are sold and consumed locally without quality control measures. Therefore, the standards have very little relevance to the poor, small scale farmers who mostly rely on maize for daily nutrition and income [2]. The high cost of mycotoxin analysis and poor infrastructure to assess food quality also makes testing of food and feed quality in Kenya difficult $[1,16]$.

Several management strategies have been employed to control aflatoxin and fumonisin accumulation in maize. These include crop rotation, breeding, fertilizer application storage systems and biocontrol among others. Breeding is considered the most environmentally sound and economical technique for controlling contamination of food and animal feed with mycotoxins [13], though currently, there is no commercial maize hybrid showing resistance to aflatoxins, and fumonisins accumulation in Africa. The available resistant parental maize lines do not have the acceptable agronomic traits, and are susceptible to mycotoxin accumulation [5, 6, 13, 17]. Information on agronomic performance of the inbred lines would be useful in choosing for parental lines with enough seedling emergence, appropriate stand establishment, uniformity in pollination and early silking lines which are important in gene mapping for early maturity $[18,19]$. In this study, maize inbred lines showing resistance to accumulation of aflatoxins, and fumonisins may be important in breeding for maize hybrids resistant to aflatoxins and fumonisins, hence the exploration to find top performing parental lines resistant to aflatoxins, and fumonisins contamination in adapted maize germplasm.

\section{Materials and Methods}

\subsection{Field Site, Experimental Design and Field Management}

The field trials were conducted between December 2013 to May 2015 at the Kenya Agricultural and Livestock Research 
Organization (KALRO), Kiboko research station [1]. Twenty-three open pollinated inbred maize lines, which included 13 genotypes from the Maize Competitive grants Initiative, International Maize and Wheat Improvement Centre (CYMMIT)-Kenya and 10 genotypes from the Agricultural Research Council's Grain Crop Institute (ARCGCI) in Potchefstroom, South African [1] were used. The trials were done in two seasons from December 2013 to May 2014 and December 2014 to May 2015. The germplasms were assessed in a randomized complete block design of three replications. Each seed was planted in a single $10 \mathrm{~m}$ long plot and spacing of $90 \times 30 \mathrm{~cm}$. Four border rows of a commercial maize hybrid were planted at each end of replication and all the recommended agricultural practices including application of fertilizer and irrigation by over-head sprinkler application were followed for each season.

Data were collected for the following agronomic traits; germination, anthesis and silking dates. The germination data was collected at 15 days after planting. Anthesis dates were recorded when $50 \%$ of the plants had shed pollen while silking dates were noted when $50 \%$ of the plants had ejected silks. Anthesis silking interval (ASI) was quantified as the difference between anthesis and silking dates of each maize inbred line [20].

\subsection{Inoculum Production}

\subsubsection{Preparation of Aspergillus Flavus Spore's Inoculum}

Three toxigenic A. flavus isolates (V201365, V100130, and V100095) previously isolated from the Makueni and Nandi counties [7] were used as inoculum for the field trials. The inoculum was prepared by weighing out $50 \mathrm{~g}$ of maize kernels into $250 \mathrm{ml}$ conical flasks. Twenty five millilitres of water was added into the flasks and covered with aluminium foil for at least 6 hours, then autoclaved at $120^{\circ} \mathrm{C}$ for 40 minutes. A sterile loop was used to transfer conidia from 5 days old A. flavus (V201365, V100130, and V100095) grown in Potato Dextrose Agar (PDA) into the cool sterile kernels, mixed well and incubated at $30^{\circ} \mathrm{C}$. Each day, the conical flasks were shaken once to prevent clumping. Fungal conidia were washed from the kernels using a soap solution composed of $40 \mu \mathrm{l}$ Tween 20 added to $20 \mathrm{ml}$. $\mathrm{H}_{2} \mathrm{O}$. Cheese cloth was used to sieve the suspension, and the conidia were collected in a beaker. A hemocytometer was used to assess conidia concentration, and a concentration of $1 \times 10^{6}$ was made using sterile distilled water. Inoculum for each of the three isolates was prepared distinctly. The conidia suspension was refrigerated at $4^{\circ} \mathrm{C}$ for not more than 72 hours and the capped plastic bottles containing conidia submerged in ice during field inoculation. Equivalent amounts of the three $A$. flavus isolates were mixed well in a conical flask wrapped with aluminium foil before performing field inoculations.

\subsubsection{Preparation of Fusarium Verticillioides Spore's Inoculum}

Three $F$. verticilloides isolates (K38, K48 and K58) held in the Mycology culture collection at the University of Nairobi, School of Biological Sciences, were used separately to prepare inoculum. These isolates were obtained from infected maize from Nandi county. Inoculum was prepared by growing $F$. verticilloides in prepared Armstrong liquid medium [21]. This was done by weighing the following: $20 \mathrm{~g}$ sucrose, $0.4 \mathrm{~g}$ magnesium sulphate $\left(\mathrm{MgSO}_{4} .7 \mathrm{H}_{2} \mathrm{O}\right), 1.6 \mathrm{~g}$ potassium chloride $(\mathrm{KCl}), 1.1 \mathrm{~g}$ potassium dihydrogen phosphate $\left(\mathrm{KH}_{2} \mathrm{PO}_{4}\right)$, 5.9g Calcium nitrate $\left(\mathrm{Ca}\left(\mathrm{NO}_{3}\right)_{2}, 20 \mu \mathrm{l}\right.$ Ferric Chloride $\left(\mathrm{FeCl}_{3}\right)$ [stock @ 10mg/ml], 20 $\mu$ l Manganese sulphate $\left(\mathrm{MnSO}_{4}\right)[\mathrm{stock} @ 10 \mathrm{mg} / \mathrm{ml}], 20 \mu \mathrm{l}$ Zinc sulphate $\left(\mathrm{ZnSO}_{4}\right)$ [stock@10mg/ml]. All the reagents were put in a media bottle and made up to 1litre (L) with sterile deionized water then autoclaved at $120^{\circ} \mathrm{C}$ for 15 minutes. Weighing of $0.1 \mathrm{~g}$ of $\mathrm{FeCl}_{3}, \mathrm{MnSO}_{4}$ and $\mathrm{ZnSO}_{4}$ was done and $10 \mathrm{ml}$ of autoclaved deionized water was added. Final concentration was then $10 \mathrm{mg} / \mathrm{ml}$ and $20 \mu \mathrm{l}$ of each solution was used in $1 \mathrm{~L}$ of Armstrong Medium.

Three toxigenic $F$. verticilloides isolates $\mathrm{K} 38, \mathrm{~K} 48$ and K58 grown in PDA were used for inoculum preparation. Into each sterile $250 \mathrm{ml}$ Erlenmeyer flask, $100 \mathrm{ml}$ of Armstrong media was poured. A sterile scalpel was used to scrape some hyphae from K38, K48 and K54 and put respectively in flasks containing $100 \mathrm{ml}$ of Armstrong medium. The number of inoculated Armstrong flasks made depended on the estimated number of cobs that were just about to silk. The flasks were placed in an incubator shaker at $25^{\circ} \mathrm{C}$ at 100 revolutions per minute (rpm) for 4 - 5 days. Fungal spores filtered by pouring through two layers of sterile cheese cloth (maximum pore size $0.7 \mathrm{~mm}$ ) into a $50 \mathrm{ml}$ falcon tube. The filtrate was centrifuged at $3500 \mathrm{rpm}$ for 5 minutes to remove the supernatant. Conidia were washed twice with de-ionized, autoclaved water of volumes equivalent to that of the original suspension. The tubes were centrifuged between washes and the spores suspended in $250-500 \mathrm{ml}$ sterile distilled water. Tween 20 surfactant (polyoxyethylene 20-sorbitan monolaurate) was added to the conidial suspension before inoculation of maize ears, at a rate of three drops per litre. For inoculation purposes, conidia concentration was adjusted to $1 \times 10^{6}$ [22]. The inoculum was kept at $4^{\circ} \mathrm{C}$ before and throughout the inoculation process. Equal quantities of the inoculum from each isolate was mixed in a conical flask wrapped in aluminium foil before inoculation.

\subsection{Field Inoculation}

Maize ears were injected with $2 \mathrm{ml}$ of inoculum using the silk-channel method [23]. Both Aspergillus, and Fusarium blocks were inoculated after at least $50 \%$ of the individual plants in a plot had emerged silks (2-6 days after silking). Inoculation was done once in the Aspergillus, and Fusarium blocks, with $A$. flavus and $F$. verticillioides inoculum respectively. Using a $10 \mathrm{ml}$ syringe and a sterile needle (gauge 18), $2 \mathrm{ml}$ of the well mixed conidial suspension was injected slowly into each maize ear. Aflatoxins susceptible inbred lines (CML 442 and VL6688) and lines characterized as susceptible to fumonisins accumulation (I137tnw and R2565Y) under natural infection were used as positive controls. All the inoculated ears were tagged/labelled for identification purposes at harvest. 


\subsection{Harvesting, Drying, and Quantification of Aflatoxins and Fumonisins Levels}

Timely harvesting was done after four weeks of physiological maturity. Drying of the maize cobs in the sun continued after harvesting for 1 week. The cobs per plot were hand shelled and seed airing continued until the grain moisture content was less than 13\% (Superpro Moisture Analyzer was used). The grains were thoroughly mixed, and in each sample, $250 \mathrm{~g}$ was collected, ground and refrigerated at $4^{\circ} \mathrm{C}$ until extraction of aflatoxins and fumonisins was done. Commercially available quantitative Enzyme-linked immunosorbent (ELISA) assay kits were used for measuring the presence of total aflatoxins and total fumonisins (Helica Biosystems Inc.).

\subsubsection{Aflatoxin Quantification}

Ground portion of the maize sample weighing $2 \mathrm{~g}$ was added to $10 \mathrm{ml}$ of $70 \%$ methanol and mixed by shaking in a sealed container for a minimum of 2 minutes. After the particulate matter had settled, $5-10 \mathrm{mls}$ of the filtrate was collected. All the reagents were brought to room temperature before use and a multi-channel pipette was used to perform the assay. Dilution wells were placed in the microwell holder for each standard and sample to be tested. Equal numbers of antibody coated microtiter wells were placed in another microwell holder and $200 \mu 1$ of conjugate was dispensed into the wells. Using a new pipette tip for each, $100 \mu 1$ of each standard and sample was added to appropriate dilution well containing conjugate and mixing was done by priming pipette at least three times followed by transfer of $100 \mu 1$ from each dilution well to a corresponding antibody coated microtiter well and incubated at room temperature for 15 minutes. Contents from the microwells were decanted and the microwells washed by filling each with deionized water, and the water was decanted again. The wash was repeated for a total of five washes. The microwells were then tapped on a layer of absorbent towels. Required volume of substrate reagent was measured $(120 \mu \mathrm{l} /$ well $)$ and placed in a separate container. Substrate reagent volume of $100 \mu 1$ was added in the same sequence and at the same pace as the substrate was added. Optical density (OD) of each microwell was read on an ELISA reader and recorded using a microtiter plate reader using a 450nm filter.

\subsubsection{Fumonisin Quantification}

Ground portion of the sample weighing $2 \mathrm{~g}$ was added to $4 \mathrm{ml}$ of the extraction solvent $(90 \%$ methanol). The mixture was shaken in a sealed bottle for 1 minute and $5-10 \mathrm{ml}$ of the filtrate was collected. The sample extract was diluted (1:20) in distilled water. All the reagents were then brought to room temperature before use and a multichannel pipette was used to perform the assay. Phosphate buffer solution (PBS) tween packet was reconstituted by washing out the contents in a gentle stream of distilled water into a $1 \mathrm{~L}$ container. One dilution well was placed in a microwell holder for each standard and sample to be tested. Equal number of antibody coated microtiter wells were placed in another microwell holder and into the dilution wells, $100 \mu$ l of conjugate solution A was dispensed followed by $100 \mu 1$ of conjugate B. Using a new pipette tip for each, $100 \mu$ l of each standard and sample were separately added to appropriate dilution well containing conjugate. Mixing was done by priming pipette three times and $100 \mu 1$ of the contents from each dilution well was transferred to a corresponding antibody coated microtiter well and incubated at room temperature for 10 minutes. Contents from the microwells were decanted, the microwells washed by filling each with PBS Tween wash buffer and the water decanted again. The wash was repeated for a total of three washes and the microwells tapped on a layer of absorbent towels to remove residual water. Using a new clean container, $120 \mu \mathrm{l} /$ well of substrate reagent was measured and placed into the container. Into each microwell, $100 \mu 1$ of the substrate was added, covered with aluminium foil and incubated at room temperature for 10 minutes. A separate container was used to place measured $120 \mu \mathrm{l} /$ well of stop solution and $100 \mu \mathrm{l}$ of the stop solution added in the same sequence and the same pace as the substrate was added. Optical density of each microwell was read and recorded using a microtiter plate reader using a $450 \mathrm{~nm}$ filter.

\subsection{Statistical Analyses}

One-way analysis of variance (ANOVA) was used to determine occurrence of significant differences in agronomic performance, and differences in aflatoxin, and fumonisin concentrations among the maize inbred lines. Where there was significant difference, Tukey's High Significant Difference (HSD) in the agricolae package [24] was used to differentiate the means at $\mathrm{P} \leq 0.05$. Pearson correlation was used for the different correlation analysis in the study. All statistical analyses were performed in $\mathrm{R} 3.2 .2$ statistical environment [25].

\section{Results}

Among the lines infected with $A$. flavus inoculum, inbred lines with significantly higher aflatoxin levels than the positive control inbred lines (CML 442 and VL06688) were P502, MIRTC5, V0617Y-2, US2540W, R119W and I137tnw while lines CB 222, CML 247, CB 248, CML 495, CML 390, CML 444, La Posta, CKL05003, CKL05015, CKL05019, CKL05022, CML 264, I137tnw, R0549W and CML 182 accumulated less aflatoxins than the positive controls. In the F. verticillioides infected lines, 15 inbred lines (CB 222, CML 444, RO549W, R119W, US2540W, V0617Y-2, CKL05019, CKL05022, CML 264, CML 442, CML 495, La Posta, MIRTC5, P502 and VL06688) accumulated fumonisin levels above the positive controls (I137tnw and R2565Y). However, six inbred lines (CB 248, CML 182, CML 390, CKL05003, CKL05015 and CML 247) showed fumonisin levels below the positive controls (Table 1). 
Table 1. Means of germination, days to silking, days to anthesis, anthesis to silking interval, kernel, aflatoxins and fumonisins accumulation.

\begin{tabular}{|c|c|c|c|c|c|c|}
\hline Genotype & $\begin{array}{l}\text { Percentage } \\
\text { Germination }\end{array}$ & Days to silking & Days to anthesis & $\begin{array}{l}\text { Anthesis silking } \\
\text { interval }\end{array}$ & Fumonisin (mg/kg) & Aflatoxin $(\mu \mathrm{g} / \mathrm{kg})$ \\
\hline $\mathrm{CB} 222^{\mathrm{SA}}$ & 77.78 & $58.00^{\text {gh }}$ & $58.33^{\text {efgh }}$ & $0.33^{\mathrm{ab}}$ & $3.82^{\text {abcd }}$ & $1.10^{\mathrm{h}}$ \\
\hline $\mathrm{CB} 248^{\mathrm{SA}}$ & 78.54 & $58.00^{\mathrm{gh}}$ & $57.17^{\mathrm{hi}}$ & $-0.83^{\mathrm{ab}}$ & $2.08^{\mathrm{bcd}}$ & $2.48^{\mathrm{h}}$ \\
\hline CML $390^{\text {SA }}$ & 89.39 & $61.67^{\mathrm{def}}$ & $61.83^{\text {cde }}$ & $0.17^{\mathrm{ab}}$ & $1.08^{\mathrm{d}}$ & $1.23^{\mathrm{h}}$ \\
\hline CML $444^{\text {SA }}$ & 74.24 & $58.00^{\mathrm{gh}}$ & $57.67^{\text {ghi }}$ & $-0.33^{\mathrm{ab}}$ & $3.86^{\mathrm{abcd}}$ & $1.36^{\mathrm{h}}$ \\
\hline I137tnw ${ }^{\text {SA }}$ & 76.01 & $58.67^{\text {fgh }}$ & $57.33^{\text {ghi }}$ & $-1.33^{\mathrm{ab}}$ & $3.19^{\text {abcd }}$ & $37.50^{\mathrm{ab}}$ \\
\hline R119W ${ }^{\mathrm{SA}}$ & 56.81 & $61.80^{\text {cdef }}$ & $61.60^{\text {cdef }}$ & $-0.20^{\mathrm{ab}}$ & $4.75^{\text {abcd }}$ & $37.60^{\mathrm{ab}}$ \\
\hline $\mathrm{R} 2565 \mathrm{Y}^{\mathrm{SA}}$ & 37.12 & $62.00^{\text {cdef }}$ & $62.17^{\mathrm{cd}}$ & $-0.43^{\mathrm{ab}}$ & $3.13^{\mathrm{abcd}}$ & $31.27^{\mathrm{abcd}}$ \\
\hline US2540W ${ }^{\text {SA }}$ & 74.24 & $56.00^{\mathrm{hi}}$ & $56.00^{\mathrm{hi}}$ & $0.00^{\mathrm{ab}}$ & $4.80^{\mathrm{abcd}}$ & $29.26^{\mathrm{bcd}}$ \\
\hline V0617Y-2 $2^{\text {SA }}$ & 81.81 & $58.33^{\text {gh }}$ & $58.67^{\text {defgh }}$ & $0.33^{\mathrm{ab}}$ & $6.21^{\mathrm{ab}}$ & $32.75^{\mathrm{abc}}$ \\
\hline CKL05003 $3^{\mathrm{KE}}$ & 80.81 & $62.33^{\text {cde }}$ & $62.33^{\mathrm{c}}$ & $0.00^{\mathrm{ab}}$ & $1.78^{\mathrm{bcd}}$ & $16.33^{\mathrm{ef}}$ \\
\hline CKL05015 $\mathrm{KE}$ & 88.89 & $62.50^{\text {cde }}$ & $61.17^{\text {cdefg }}$ & $-1.33^{\mathrm{ab}}$ & $2.74^{\text {abcd }}$ & $8.88^{\text {fgh }}$ \\
\hline CKL05019 & 84.34 & $63.50^{\text {bcd }}$ & $62.50^{\mathrm{c}}$ & $-1.00^{\mathrm{ab}}$ & $3.30^{\mathrm{abcd}}$ & $4.28^{\mathrm{h}}$ \\
\hline CKL05022 $2^{\mathrm{KE}}$ & 82.83 & $62.00^{\text {cdef }}$ & $62.83^{\mathrm{bc}}$ & $0.83^{\mathrm{ab}}$ & $3.74^{\mathrm{abcd}}$ & $4.50^{\mathrm{h}}$ \\
\hline CML $264^{\mathrm{KE}}$ & 61.87 & $67.50^{\mathrm{a}}$ & $66.17^{\mathrm{ab}}$ & $-1.33^{\mathrm{ab}}$ & $4.12^{\mathrm{abcd}}$ & $6.97^{\text {gh }}$ \\
\hline CML $442^{\mathrm{KE}}$ & 76.26 & $66.25^{\mathrm{ab}}$ & $64.50^{\mathrm{abc}}$ & $-1.75^{\mathrm{b}}$ & $4.34^{\mathrm{abcd}}$ & $25.26^{\mathrm{cd}}$ \\
\hline CML $495^{\mathrm{KE}}$ & 85.10 & $62.16^{\text {cde }}$ & $63.50^{\mathrm{bc}}$ & $1.33^{\mathrm{ab}}$ & $3.49^{\mathrm{abcd}}$ & $1.09^{\mathrm{h}}$ \\
\hline La Posta ${ }^{\mathrm{KE}}$ & 75.76 & $64.80^{\mathrm{abc}}$ & $68.00^{\mathrm{a}}$ & $3.20^{\mathrm{a}}$ & $4.53^{\mathrm{abcd}}$ & $2.03^{\mathrm{h}}$ \\
\hline MIRTC5 $5^{\text {KE }}$ & 80.30 & $61.83^{\text {cdef }}$ & $61.33^{\text {cdef }}$ & $0.00^{\mathrm{ab}}$ & $5.76^{\mathrm{abc}}$ & $30.80^{\mathrm{abcd}}$ \\
\hline P502 ${ }^{\mathrm{KE}}$ & 76.01 & $59.83^{\text {efg }}$ & $58.00^{\text {fghi }}$ & $-1.83^{b}$ & $3.50^{\mathrm{abcd}}$ & $38.37^{\mathrm{a}}$ \\
\hline VL06688 KE & 75.51 & $54.20^{\mathrm{i}}$ & $54.60^{\mathrm{i}}$ & $0.40^{\mathrm{ab}}$ & $6.76^{\mathrm{a}}$ & $25.84^{\mathrm{cd}}$ \\
\hline
\end{tabular}

Key- Means followed by the same letter are not significant from each other

$\mathrm{KE}=$ origin from Kenya ${ }^{\mathrm{SA}}=$ origin from South Africa

The maize inbred lines were different $(\mathrm{P}=<2.2 \mathrm{e}-16)$ in seedling emergence and germplasm CML 390 germinated best compared to any other inbred line. Other good germinating lines included CKLO5015, CML 495, CKLO5019 and CKLO5022 while R2565Y was the poorest germinator. Time taken to silking among the inbred lines differed significantly $(\mathrm{P}=<2.2 \mathrm{e}-16)$. Line V0617Y-2 silked earliest compared to other lines while CML 247 silked latest. Variation occurred in the pollen shedding period among the inbred lines $(\mathrm{P}=<2.2 \mathrm{e}-16)$ and among the inbred lines, US2540W shed pollen earliest while CML 247 shed its pollen latest. Approximately, $95.65 \%$ recorded ASI between 2 to 2 days, except La Posta (Table 1). A positive correlation occurred between day to anthesis (DA) and days to silking (DS), anthesis silking interval (ASI) and days to silking (DS), aflatoxins and fumonisins $(\mathrm{r}=0.43149988, \mathrm{P} \leq 0.05)$ accumulated by the inbred lines as shown in Table 2 . Significant negative correlations $(P \leq 0.05)$ were revealed between aflatoxins levels in the inbred lines and the number of days to anthesis $(r=-0.4617732)$, germination rate and accumulated fumonisins $(\mathrm{r}=-0.5156961)$ (Table 2).

Table 2. Pearson correlation coefficients of agronomic traits, aflatoxin and fumonisin levels in maize inbred lines.

\begin{tabular}{lllll}
\hline & Germination & DA & DS & Aflatoxins \\
\hline DA & & & $0.9458846^{* *}$ & \\
ASI & & & $0.04992592^{*}$ & $-0.3632241^{*}$ \\
Aflatoxins & $-0.3772456 *$ & $-0.4617732 * *$ & $-0.3697669^{*}$ & $-0.05282994 *$ \\
Fumonisins & $-0.5156961 * *$ & $-0.1222758^{*}$ & $-0.1130637^{*}$ & $0.43149988^{* *}$ \\
\hline
\end{tabular}

**r is significant at $\mathrm{P} \leq 0.05$ level, $\mathrm{r}$ is significant at $\mathrm{P} \leq 0.01$ level

Key: DA- days to anthesis, DS-days to silking, ASI-anthesis silking interval

\section{Discussion}

Seeds with delayed germination rates like R2565Y are likely to reduce the yield of individual plants in a stand, therefore, every breeder would prefer seeds with high germination rates (CML 390, CML 495, CKL050150 and CKL05019). Crop yield and efficiency of resource is determined by successful establishment of the plant in the field and poor germinating lines (R2565Y-2, R119W and CML 264) are likely to affect crop yield especially when grown in areas where the growing season is short since in such areas, the crops must have their developments faster in order to maximize yield. Further still, performance of $F_{1}$ greatly depends on the parent lines used in developing crosses [26] which makes most breeders select for maize lines with fast, uniform germination and seedling emergence in order to maximize on yield. In addition to fast stand establishment, the short ASI (-2 to 2 days) recorded by the inbred lines would be an important trait in consideration during breeding. Among the inbred lines, $48.7 \%$ of the lines presented negative ASI which is a drought escaping phenomenon signalled by the occurrence of silking before tassels were produced. The short ASI is associated with drought tolerance because the genotypes make 
use of the limited moisture more efficiently during flowering [20]. Selection of maize lines with short ASI is an effective approach for synchronisation for male and female flowering under stress [17]. This trait together with other useful secondary traits can be used by breeders for selecting parental lines for breeding purposes. A significant positive correlation between days to anthesis and silking occurred as would be expected ( $\mathrm{r}=0.9458846, \mathrm{P}=<9.845 \mathrm{e}-12$ ) (Table 2). This would enable successful timing of outcrossing between two targeted inbred lines determined by the silking and pollen shed days. However, some studies have reported highly significant negative correlations between ASI and days to silking, and days to anthesis [20]. In our study, there were no significant correlations between ASI and DA $(r=0.03961208, \mathrm{P}=$ $0.8576)$, and ASI and DS $(r=0.04992592, \mathrm{P}=0.821)$. This shows that phenotypic correlations alone are not enough to determine close linkages between genes, but further studies focussed on genetic linkage of the genes controlling the specific traits need to be undertaken to verify whether the genes are closely linked or not.

Lines CB 222, CML 495, CML 390, CML 444, CML 247 accumulated least aflatoxin levels below $10 \mu \mathrm{g} / \mathrm{kg}$. In a different study [1], CB 222, CML 444, CML 495, CML 247 and CML 390 were reported to be resistant to $A$. flavus infection and subsequent accumulation of aflatoxin. A dissimilar study reported resistance to aflatoxin accumulation in CML 247 [27]. Further still, low aflatoxin accumulation and low AER has been documented in CML 247 [1]. In this study, germplasms CML 390, CML 247 and CKL05003 accumulated fumonisin levels below $2 \mathrm{mg} / \mathrm{kg}$. It is also encouraging to note that CML 390 and CML 247 accumulated lowest fumonisin and aflatoxin levels. In a study conducted to determine resistance to infection by $F$. verticillioides and subsequent accumulation of fumonisins, line CML 390 was found to be resistant to Fusarium ear rot (FER) and fumonisin accumulation [6]. Therefore, CML 390 and CML 247 germplasms may be useful sources of resistance in maize breeding programs targeted at lowering both aflatoxin and fumonisin contamination. As expected, some maize inbred lines showed resistance only to aflatoxin instead of fumonisin contamination, and vice versa (Table 1). Lines CML 264, CML 495, and La Posta accumulated aflatoxin levels below $10 \mu \mathrm{g} / \mathrm{kg}$ and fumonisin above $2 \mathrm{mg} / \mathrm{kg}$. Likewise, to CKL05003, which accumulated fumonisin levels below 2 $\mathrm{mg} / \mathrm{kg}$ and aflatoxin $<10 \mu \mathrm{g} / \mathrm{kg}$. However, these lines may have different levels of resistance when evaluated in different environments. They could be suitable for mapping populations directed at identifying quantitative trait loci (QTL) involved in resistance to infection by $A$. flavus or $F$. verticilloides and contamination by aflatoxins, and fumonisins respectively. Though a positive correlation $(\mathrm{r}=0.4314998, \mathrm{P}>0.05)$ occurred between aflatoxin and fumonisin levels in the inbred lines, the correlation coefficient was low. Selection of inbred lines with low aflatoxin levels would not probably select for lines with low fumonisin levels in most cases. For example, CML 495 accumulated very low aflatoxin levels $(1.09 \mu \mathrm{g} / \mathrm{kg})$ but recorded fumonisins above $2 \mathrm{mg} / \mathrm{kg} \quad(3.49 \mathrm{mg} / \mathrm{kg})$. A previous study found a positive correlation between aflatoxin and fumonisin levels in the inbred maize lines and further assessment of a collection of germplasms for resistance is recommended [20]. The QTL analysis would therefore determine if there are common loci for the aflatoxins, and fumonisins resistant phenotypes.

\section{Conclusion}

Early germination and short ASI are important in mapping for early maturity. The inbred lines had a short ASI of between -2 to 2 days except La Posta (3 days) which is an indication of presence of a drought tolerant trait. Apart for selecting for early maturity, most breeders would prefer lines that accumulate aflatoxins and fumonisins below the positive controls. Lines CML 390 and CML 247 would be preferable because despite having short ASI, and good germination rates, they accumulated least aflatoxin and fumonisin levels compared to the other inbred lines. The two lines could be useful sources for breeding for resistance to aflatoxins and fumonisins. Aflatoxin (CB222, CML 495 and CML444) and fumonisin (CKL05003) resistant lines could be investigated further for inclusion into maize breeding program for resistance to aflatoxins, and fumonisins respectively. In the study, not all inbred lines that accumulated low aflatoxin levels recorded low fumonisins and vice versa. Lines CML 495, La Posta, CML 444, CB 248 and CB 222 had aflatoxin levels below $10 \mu \mathrm{g} / \mathrm{kg}$ and fumonisins above $2 \mathrm{mg} / \mathrm{kg}$ while CKL05003 showed resistance to fumonisin but was susceptible to aflatoxin accumulation. Further investigation on the genes controlling resistance to aflatoxins and fumonisins accumulation in maize is recommended.

\section{Data Availability}

The [DATA TYPE] data used to support the findings of this study are available from the corresponding author upon request.

\section{Conflicts of Interest}

All the authors do not have any possible conflicts of interest.

\section{Funding}

The MAIZE Competitive Grants Initiative, International Maize and Wheat Improvement Centre (CIMMYT)-Kenya, is acknowledged for funding this research through the project, 'Maize breeding for resistance to aflatoxins and fumonisins in eastern and southern Africa.' Project number A4032.09.2.

\section{References}

[1] Okoth, S., Lindy, J. R., Ouko, A., Beukes, I., Sila, H., Mouton, M., Flett, B. C., Makumbi, D., Viljoen A. (2017). Field evaluation of resistance to aflatoxin accumulation in maize inbred lines in Kenya and South Africa. Journal of Crop Improvement, 31: 862-878. 
[2] Okoth S. (2016). Improving the evidence base on aflatoxin contamination and exposure in Africa. Agriculture and nutrition, Review. CTA working paper 16/13.

[3] Kang'ethe E. K., Gatwiri M., Sirma A. J., Ouko e. O., Mburugu-Mosoti C. K., KitalaP. M., Ndihiu G. J., Nderitu J. G., Mungatu J. K., Hietaniemi V., Joutsjoki V., Korhonen H. J. (2017). Exposure of Kenyan population to aflatoxins in foods with special reference to Nandi and Makueni counties," Food Quality and Safety, 1: 131-137.

[4] MacRobert, J. F., Setimela P. S., Gethi J., Worku M. (2014). Maize. Hybrid Seed Production Manual. Mexico, D. F.: CIMMYT. ISBN: 978-607-8263-264.

[5] Rose L., Sheila O., Beukes I., Abigael O., Mouton M., Bradley C., Makumbi D., Altus V. (2017). Determining resistance to Fusarium verticillioides and fumonisin accumulation in African maize inbred lines resistant to Aspergillus flavus and aflatoxins. Euphytica, 213: 93.

[6] Rose L., Mouton M., Beukes I. (2016). Multi-environment evaluation of maize inbred lines for resistance to Fusarium ear rot and fumonisin. Plant Disease, 100: 10.

[7] Okoth S., Nyongesa B., Ayugi V., Kangethe E., Korhonen H., Vesa J. (2012). Toxigenic potential of Aspergillus species occurring in maize kernels from two agro- ecological zones. Toxins, 4: 491-1007.

[8] Bii, F., Wanyoike W., Nyande A. B., Gituru R. W., Bii C. (2012). Fumonisin contamination of maize (Zea mays) in aflatoxin hot zones in Eastern Province of Kenya. African Journal of Health Sciences 20: 28-36.

[9] Probst, C., Njapau H., Cotty P. J. (2007). Outbreak of an acute aflatoxicosis in Kenya in 2004: Identification of the causal agent. Applied and Environmental Microbiology, 73: 2762-64.

[10] Suleiman R. A. and Rosentrater K. A. (2015). Current maize production, post-harvest losses and the risk of mycotoxins contamination in Tanzania. Agriculture, 1-128.

[11] Mwalwayo D. and Thole B. (2016). Prevalence of aflatoxin and fumonisins $\left(\mathrm{B}_{1}+\mathrm{B}_{2}\right)$ in maize consumed in rural Malawi. 3(173-179).

[12] KBS (Kenya Bureau of Standards), 2013. The Benchmark. The official magazine of the Kenya Bureau of Standards, Issue 19, pp 39.

[13] Guo B., Xiangyun J., Xinzhi N., Jake C., Hong L., Hammed K., Robert D., Brian T. (2017). Evaluation of maize inbred lines for resistance to pre-harvest aflatoxin and fumonisin accumulation in the field. Crop Journal, 259-264.

[14] Obura A. (2013) Aflatoxins: Finding solutions for improved food safety. Aflatoxicosis: Evidence from Kenya. Agriculture for Nutrition and health.
[15] Wagacha J. M. and J. W. Muthomi (2008). Mycotoxin problem in Africa: Current status, implications to food safety and health and possible management strategies. International Journal of Food Microbiology, 124: 1-12.

[16] Kibe N. (2015). Thesis. Occurrence of mycotoxigenic fungi in maize from food commodity markets in Kenya. Ghent university.

[17] Bernahu T. E., Beyeni Y., Biswanata D., Mugo S., Olsen M., Oikeh S., Juma C., Labuschagne M., Prasanna B. M. (2017). Combining ability and test cross performance of drought tolerant maize inbred lines under stress and non-stress environments in Kenya. Plant breeding 136,197-205.

[18] Finch-Savage W. E. and Bassel G. W. (2016). Seed vigour and crop establishment: extending performance beyond adaptation. Journal of experimental Botany, 67: 567-591.

[19] Harmeet S., Rupinder K. J., Kang J. S., Sandhu S. S., Harrajdeep K., Kamaljit G. (2015). Seed priming techniques in field crops - Agriculture, Review, 36 (4): 251-264.

[20] Ngugi K., Jerono C., Muchira C. and Chemining'wa G. (2013). Anthesis to silking interval usefulness in developing drought tolerant maize. Journal of renewable agriculture, 1(5): 84-90.

[21] Booth C (1971) The genus Fusarium. Commonwealth Mycological Institute, Kew, p 237.

[22] Small M., Flett C., Marasas W., McLeod A., Stander M., Viljoen A. (2012) Resistance in maize inbred lines to Fusarium verticillioides and fumonisin accumulation in South Africa. Plant Diseases, 96: 881-888.

[23] Zummo, N., and Scott G. E. (1989). Evaluation of field inoculation techniques for screening maize genotypes against kernel infection by Aspergillus flavus in Mississippi. Plant Diseases, 73: 313-16.

[24] Felipe de Mendiburu (2017). agricolae: Statistical Procedures for Agricultural Research. $\mathrm{R}$ package version 1.2-8. http://CRAN. R-project.org/package=agricolae.

[25] R Core Team (2015). R: A language and environment for statistical computing. R Foundation for Statistical Computing, Vienna, Austria. URL https://www.R-project.org/.

[26] Bushra M. and Jones D. A. (1983). The genetics of maize (Zea mays L.) growing at low temperatures. Euphytica, 32 (2) 535542.

[27] Williams, W. P., Krakowsky M. D., Scully B. T., Brown R. L., Menkir A., Warburton M. L., Windham G. L. (2014). Identifying and developing maize germplasm with resistance to accumulation of aflatoxins. World Mycotoxin, 8 (2): 193 209. 